\title{
Arbor
}

\section{La Sanidad ¿patrimonio único?}

\section{Gaspar Llamazares Trigo}

Arbor CLXXX, 710 (Febrero 2005), 389-396 pp.

Con este título genérico, la revista ARBOR nos propone analizar la situación de la sanidad española tras las transferencias del año 2002, valorar las deficiencias detectadas, las incertidumbres que lo envuelven y qué propuestas hace cada uno desde su particular perspectiva.

No cabe otra respuesta que el reconocimiento a la revista por haber valorado como interesante contar con la perspectiva de IU y hacer un esfuerzo de síntesis para aportarla de la mejor manera posible. Vamos a ello.

Efectivamente el año 2002 marca un hito en la construcción del Sistema Nacional de Salud. Por primera vez desde el 1 de enero de ese año, se acaban de cumplir tres años de aquella fecha, todas las CCAA son competentes en la gestión de los servicios sanitarios. Por primera vez, de forma efectiva, la España de las Autonomías incorpora una gestión descentralizada del sistema sanitario.

IU ha sido defensora, desde su misma creación, por una parte de un Estado Federal y por otra de un sistema sanitario público universal, equitativo, de calidad y sostenible. Estas dos ideas guía siguen en el momento actual sirviendo de norte a nuestra organización y a toda su actividad política en el ámbito que nos ocupa.

Pensamos que un modelo federal del estado es la mejor "plantilla» para ofrecer situaciones favorables para el conjunto de partes que forman España, además de servir, como mejor cauce, para el desarrollo armónico del conjunto y de cada una de sus partes.

Igualmente creemos que un sistema sanitario público, que llegue a toda la población, que no plantee barreras a los ciudadanos en su acceso, que sea proporcionado a las diferentes necesidades de cada uno de ellos, que al hacer del ciudadano su protagonista, pueda finalmente ofrecer servicios seguros y de calidad, es la mejor respuesta al derecho a la salud reconocido en la Constitución de 1978. 
Pero ambas ideas, en la medida que actúan como ideas reguladoras, deben ser permanentemente contextualizadas para hacer posible una práctica política pegada al terreno, como es nuestra intención.

Cierto es que desde 1978 hasta la hoy los cambios en nuestro país han sido gigantescos. No sólo la Ley General de Sanidad y su desarrollo o las trasformaciones en el sector de los servicios sanitarios, sino los cambios sociológicos, económicos y políticos del entorno han sido de tal envergadura que nos obligan a todos, e insisto en el «todos», a un ejercicio intenso de reflexión, de repensar que significan hoy las palabras, los conceptos de ayer. IU hace ese ejercicio con el mayor interés, no sólo para tener más probabilidades de acertar en sus propuestas, sino porque creemos que es una de las formas adecuadas de contribuir a los consensos necesarios para sustentar uno de los servicios esenciales para cualquier sociedad avanzada como es el sanitario.

En esta clave es en la que me propongo repasar sucintamente tres grupos de asuntos que pueden reflejar nuestra posición general en el debate que nos ocupa: Los problemas heredados, los condicionantes del entorno actual y los desafíos para el futuro.

\section{Los problemas heredados}

Ni me voy a referir a todos, ni la denominación de problemas heredados quiere ser una crítica a todos los que en los últimos 27 años han trabajado en el sector, profesional o políticamente. Pero no puede dudarse que el pasado nos condiciona, de hecho creo que todos podemos acordar que algunas de las notas fundamentales de nuestra agenda se refieren esencialmente a cómo superar esos «problemas heredados». Resaltaré sólo cuatro:

\section{El modelo de financiación}

En España hemos pasado de una financiación proveniente de la Seguridad Social a otra proveniente de los presupuestos generales del estado y finalmente a la actualmente vigente que descansa en el modelo general de financiación de las CCAA. El avance que esto supone no se oculta a nadie. El problema se plantea cuando uno se da cuenta de que la financiación del sistema, tanto en unas fórmulas como en otras siempre ha sido escasa. Escasa no significa que la cantidad sea pequeña, significa que ha ido por debajo de lo que otras sociedades emplean en man- 
tener sus servicios sanitarios, lo que necesariamente conlleva la generación sistemática de déficit. Este es uno de los problemas fundamentales, aunque no el único. España, en su conjunto puede y debe incrementar el porcentaje de PIB que emplea en sanidad, y especialmente en el tramo público de ese gasto. Sin embargo el nuevo modelo de financiación de las CCAA, además de no resolver este problema, por su propia naturaleza puede convertirse en un factor generador de mayores desequilibrios territoriales, al no prever mecanismos efectivos de cohesión que corrijan las diferentes capacidades recaudatorias de las CCAA.

Sin embargo, y estos es fundamental reconocerlo, la solución no es simplemente echar más carbón a la caldera. Si el tren lleva el mismo camino y emplea ese carbón de la misma forma, en poco tiempo nos encontraremos en la misma situación. No obstante quede claro que tenemos un problema evidente de financiación, y que este ni es nuevo ni puede imputarse a las CCAA.

El objetivo de cualquier revisión del modelo de financiación debería recoger los siguientes criterios:

1. El gasto sanitario público debe incrementarse entorno a un punto.

2. La corresponsabilidad de las CCAA en la financiación no debería suponer la generación de una asimetría en las prestaciones sanitarias en el conjunto del estado.

3. La diferenciación de las prestaciones por decisión de una CCAA debería tener algún límite, y ese límite debería consensuarse en el seno del Consejo Interterritorial. De lo contrario el factor liebre sería difícilmente controlable para el conjunto.

4. La financiación debería ser en sí misma un elemento favorecedor de la equidad y la cohesión, no lo contrario.

\section{El modelo de relaciones laborales}

La política de recursos humanos en la función pública española, y especialmente en la sanidad, ha sido, cuando ha existido un ejemplo de lo que se debería hacer. Después de la operación «Villalobos» parece que estamos a punto de terminar con una de las lacras de nuestro sistema: la interinidad. Pero más allá de esto, que tiene su importancia, el problema es que tenemos unas plantillas y unas tipologías de relaciones laborales muy poco adecuadas a las necesidades del sistema. 


\section{La cultura de empresa}

Pero si la financiación y las relaciones laborales son importantes, uno de los mayores problemas que tiene el sistema sanitario es su cultura de empresa. Efectivamente lo que hoy se espera de servicio público está ya lejos de lo que podían ser las expectativas de los ciudadanos hace más de veinte años. $\mathrm{Y}$, sin embargo, es precisamente esa la cultura que todavía tiene nuestra sanidad. Los políticos y especialmente los gerentes tenemos por delante uno de los mayores desafíos a la hora de modernizar nuestra cultura de servicio. Es natural que una burocrcia profesional como es la sanidad, muchos de cuyos valores, rutinas y fórmulas organizativas responden más a los intereses de los trabajadores que a los de los ciudadanos, se resista a cambiar. Pero en ello nos van dos cuestiones íntimamente relacionadas: la calidad del servicio, en este caso medida en términos de calidad percibida, o satisfacción, y la legitimidad social del sistema.

Por ello, aun cuando cueste y exija tomar decisiones difíciles que probablemente generen algún tipo de conflicto, es inaplazable invertir en «cambio cultural».

Para IU es un desafío difícil, pues somos una fuerza estrechamente ligada a los trabajadores, pero si queremos mejorar nuestro sistema debemos comprometernos con un cambio en la cultura de nuestras organizaciones o las estaremos debilitando y con ello al conjunto de los ciudadanos.

\section{La distribución del binomio autoridad-responsabilidad}

El carácter ilustrado de nuestra sociedad: «todo para el pueblo pero sin el pueblo" que aún se mantiene en muchos ámbitos, debe dar paso al reconocimiento efectivo de la mayoría de edad de la ciudadanía. Mayoría que no se puede reducir a votar cada cuatro años.

Es evidente para cualquiera, que desde la Ley General de Sanidad no se han desarrollado los tímidos mecanismos de participación que en ella se preveían. Son 19 años perdidos en esta cuestión. IU entiende que la autoridad de los gobiernos y sus agentes no es suficiente para garantizar la gobernabilidad del sistema. No sólo por razones del más estricto pragmatismo, sino también por razones de salud democrática. Nuestros ciudadanos no podrán tener el grado de identifiación con el servicio que requiere una sociedad moderna sino tienen formas, muchas y efectivas formas de participar en su orientción, gestion y mejora. Cualquier plan- 
teamiento alicorto, tímido o temeroso de la participación no puede conducir a otro escenario que un progresivo divorcio entre el sistema y los agentes sociales y los ciudadanos.

Es lamentable que la participación, en las discusiones más habituales del momento sobre el tema, sea como hacer «participar» a los ciudadanos en la financiación mediante múltiples formas de copago.

IU cree que los ciudadanos ya pagan el servicio, y sin embargo no reciben todo lo que este puede darles. Quizá haya que replantearse no ya el copago de los ciudadanos, sino los «ingresos» que gracias al sistema tienen muchos agentes que obtinen de él sabrosos beneficios.

IU no se niega a hablar de modificar los mecanismos actuales de copago. Pero creemos que nos es justo que eso no implique un análisis previo y la adopción de medidas inmediatas sobre el rapatrto de cargas y beneficios de otros agentes. Señaladamente las empresas de tecnológia médica, las empresas farmacéuticas, determinados estilos políticos y gerenciales que contribuyen al aumento de la ineficiencia del sistema, y ciertos grupos de profesionales cuya práctica se aparta de los mejores criterios científicos y deontológicos en su área de trabajo.

\section{Los condicionantes del entorno actual}

Junto al pasado, son los valores actuales de los parámetros básicos de la sociedad (podría decirse de las prácticas sociales mayoritarias, de la interpretación que la mayoría hace de esas prácticas y de los consensos básicos sobre el cómo deberán ser en el futuro), los elementos que determinan las posibilidades de elección de cualquier agente social, señaladamente de los agentes políticos. Acertar en este asunto es básico para valorar la viabilidad de nuestras propuestas.

Como en el caso anterior no mencionaré más que algunos de estos condicionantes:

\section{Los servicios de salud: bien necesario, escaso o de consumo}

No entraré a hacer valoraciones académicas de hondo calado académico. Pero sí me permitiré un par de reflexiones.

Los servicios sanitarios han pasado a convertirse en un bien de consumo. Con ello quiero decir que cualquier ciudadano español tiene, al relacionarse con los servicios de salud, una actitud que no se diferencia mucho de la que tiene cuando va a un hotel de vacaciones, o a un gran 
almacén a comprar. La importancia de este cambio de actitud en los usuarios es tremenda para el sistema.

La exigencia, las expectativas, la búsqueda de alternativas, es algo que el ciudadano aprende en su vida cotidiana y que traslada, cada día con más fuerza a su trato con el servicio sanitario.

No entender esto en los enfoques políticos, en la gestión y en la forma de trabajar, en la cultura, decía antes, puede poner en peligro la supervivencia del sistema sanitario público.

IU no cree que los valores culturales de una democracia de mercado sean ni los mejores ni los únicos posibles. Por eso para nosotros es fundamental valorar este fenómeno y desarrollar políticas, alianzas y propuestas que puedan aprovehcar su energía para mejorar el sistema sin por ello desnaturalizarlo.

\section{Tensiones en el reparto de la tarta presupuestaria}

En el título anterior se hablaba de «bien escaso». Sin duda los recursos que se pueden destinar a sanidad siempre sarán limitados. Este no es el problema. La cuestión es si destinamos a la sanidad una parte adecuada a nuestras posibilidades, es decir si la sanidad tiene, en el reparto presupuestario del esfuerzo de las diferentes administraciones, un peso adecuado a nuestras preferencias sociales.

IU, ya lo reseñe antes, cree que no. Pero es que además el otro problema que tenemos es, que los servicios sanitarios tienen que demostrar día a día con su trabajo, que son una inversión rentable en términos sociales, es decir que son algo más que una pozo sin fondo para alimentar a grandes corporaciones industriales o a poderosos grupos profesionales.

\section{Inercia o el riesgo político del cambio, burocracias profesionales y status quo Equidad y beneficios}

Dicen que la sanidad no hace ganar elecciones pero que las puede hacer perder. Este es quizá uno de los más intrincados problemas a los que nos tenemos que enfrentar. ¿En qué medida estamos los políticos dispuestos a gastar parte de nuestro "crédito electoral» por adoptar medidas duras en el sector sanitario; y no e refiero al copago, me refiero a asumir confrontaciones importantes con grandes corporaciones financieras, industriales, profesionales o sindicales, si ello fuera necesario para desarrollar políticas de interés general?. En este caso mi pesimismo es gran- 
de. Tengo la sensación de que el tipo de políticas que se hacen, tienen más que ver con la prevención de que «ciudado que este conflicto no me cueste las próximas elecciones» que con la conveniencia de las decisiones que deban tomarse.

Uno de los síntomas más preocupantes, de que esta dinámica tán «prudente» como estéril parece mayoritaria, es la forma tan irresponsable en la que se utilizan los problemas con las listas de espera o las crisis de Salud Pública que se producen a nivel local y algunas decisiones sobre cartera de servicios, política de carrera profesional, acuerdos sindicales, etc.

En el sistema juegan agentes muy poderosos. La mayoría de las fuerzas políticas no se atreve a abordar de frente los problemas. Como mucho a que parezca que algo mejora, incluso a riesgo de aumentar las tensiones de fondo, -el que venga detrás que arree-, con tal de que no verse afectados electoralmente.

A mi juicio una parte sustancial del problema puede ser que la mayoría de las fuerzas políticas acepten, unas con entusiasmo otras resignadamente, que la alternativa al deterioro del sistema público, es decir el privado, no sea, con su impacto en la equidad, un precio a pagar demasido grande si a cambio consiguen el apoyo, o al menos la neutralidad, de todas esas corporaciones que hemos mencionado anteriormente.

IU confía plenamente en que aún hay muchos agentes sociales, muchos políticos y una inmensa mayoría de ciudadanos que apoyaría a cualquiera que hablara claro y pusiera encima de la mesa "agenda y propuestas valientes".

\section{Los desafios para el futuro}

No existen soluciones mágicas, ni siquiera un conjunto cerrado de soluciones, tengan este o aquel color. Si bien no cabe duda de que el futuro nos deparará un sistema sanitario que no satisfará a ningún actor plenamente y eso no debe impedir que seamos capaces de establecer nuestra propia perspectiva junto a nuestra disposición a sumar voluntades, lo bueno es enemigo de lo mejor.

Consignaré muy pocos de los desafíos que tiene por delante el sistema sanitario. Pero me parece oportuno destacar que los desafíos no son iguales, ni en género ni en especie. No son lo mismo los desafíos para un político que para un economista de la salud, un jefe de servicio o una enfermera o un ciudadano. Tampoco son iguales los desafíos para un político del PP que para uno de IU. Por ello adquiere mayor relevancia que 
seamos capaces de mantener el consenso básico sobre lo que debe perseguir el sistema sanitario público, pudiendo discrepar en los medios para alcanzarlo, siempre dentro de ciertos límites.

En coherencia con lo dicho en el apartado anterior debería ahora poner encima de la mesa lo que antes reclamaba: propuestas claras y valientes.

Pero el espacio asignado a este artículo hace líneas que está desbordado y, sin embargo, el argumento es largo. Pero no sólo por ello me limitaré ahora a enunciar los apartados que al menos debería tener esa agenda. También lo hago porque creo que nuestro problema hoy en relación a la sanidad no es de argumentos o propuestas, sino de voluntad política. De configurar mayorías políticas dispuestas a hablar, acordar y aplicar medidas que no siempre habrán de resultar cómodas a corto plazo.

\section{Liderazgo}

El papel del sistema sanitario en el conjunto social

Participación, corresponsabilidad y financiación

Equidad y sostenibilidad

La reformulación de la continuidad asistencial (el desafío socio-sanitario)

Calidad y seguridad

He tratado siquiera de mencionar algunos de los asuntos que a nuestro juicio deberían situarse en la agenda política de quienes tenemos la obligación de dotar de horizontes de futuro a nuestro sistema sanitario. Por parte de IU podemos comprometer nuestra disponibilidad para contribuir a los procesos de debate y construcción del consenso necesario para aportar al sistema estabilidad, ilusión, directrices claras, apoyo político e ideas que permitan mantener a la sanidad como uno de los servicios más valorados por la sociedad, un servicio clave en el estádo del bienestar, factor de equilibrio y justicia social. En cualquier caso espero haber podido indicar algunas de nuestras ideas sobre este patrimonio común que es la sanidad pública. 